\title{
MicroRNA-103a-3p promotes metastasis by targeting TPD52 in salivary adenoid cystic carcinoma
}

\author{
MIN FU ${ }^{1,2^{*}}$, CHU-WEN CHEN $^{1 *}$, LIN-QIAN YANG $^{1}$, WEN-WEN YANG ${ }^{1}$, \\ ZHI-HAO DU ${ }^{1}$, YIN-RAN LI ${ }^{1}$, SHENG-LIN LI ${ }^{1,2}$ and XI-YUAN GE ${ }^{1,2}$ \\ ${ }^{1}$ Central Laboratory, Peking University School and Hospital of Stomatology, National Clinical Research Center \\ for Oral Diseases, National Engineering Laboratory for Digital and Material Technology of Stomatology, \\ Beijing Key Laboratory of Digital Stomatology; ${ }^{2}$ Department of Oral and Maxillofacial Surgery, \\ Peking University School and Hospital of Stomatology, Beijing 100081, P.R. China
}

Received September 19, 2019; Accepted May 5, 2020

DOI: 10.3892/ijo.2020.5069

\begin{abstract}
Salivary adenoid cystic carcinoma (SACC) exhibits slow continuous growth, frequent local recurrences and a high incidence of blood metastasis, with advanced lung metastasis frequently occurring and being among the primary causes of mortality. MicroRNAs (miR) serve a significant role in the initiation and development of cancer and may be tumour-specific molecular targets. However, the role of miR-103a-3p in SACC remains largely unknown. In the present study, the expression levels of miR-103a-3p and tumour protein D52 (TPD52) were detected by reverse transcription-quantitative PCR. In addition, wound-healing assays, Transwell assays and mouse models of lung metastasis were used to investigate the biological functions exerted by miR-103a-3p. The present results suggested that miR-103a-3p expression was significantly upregulated in SACC samples. Gain-of-function and loss-of-function studies in SACC cells demonstrated that miR-103a-3p acted as an oncogene by promoting tumour cell migration in vitro and lung metastasis in vivo. Dual-luciferase reporter gene assays indicated that miR-103a-3p exerted its regulatory functions by binding to the $3^{\prime}$ untranslated region of TPD52 mRNA. TPD52 overexpression rescued the effect of miR-103a-3p on promoting SACC cell migration, suggesting that miR-103a-3p acted as an oncogene to promote cancer metastasis by directly targeting
\end{abstract}

Correspondence to: $\mathrm{Dr}$ Sheng-Lin $\mathrm{Li}$ or Dr Xi-Yuan Ge, Department of Oral and Maxillofacial Surgery, Peking University School and Hospital of Stomatology, 22 South Zhongguancun Avenue, Beijing 100081, P.R. China

E-mail: kqshlli@bjmu.edu.cn

E-mail: gexiyuan@bjmu.edu.cn

${ }^{*}$ Contributed equally

Abbreviations: SACC, salivary adenoid cystic carcinoma; miRNA/miR, microRNA; RT-qPCR, reverse transcription-quantitative PCR

Key words: SACC, miR-103a-3p, metastasis, Tumour protein D52
TPD52. Thus, the newly identified miR-103a-3p/TPD52 axis contributes to the understanding of SACC pathogenesis, providing insights into the identification of novel biomarkers or potential therapeutic targets in SACC.

\section{Introduction}

Salivary adenoid cystic carcinoma (SACC) is a common malignant tumour of the salivary glands (1). Compared with other malignant tumours, SACC has unique biological features, such as slow and continuous proliferation, frequent local recurrence and high incidence rates of blood, nerve and advanced lung metastasis, but a rare occurrence of lymphatic metastasis $(2,3)$. Moreover, distal lung metastasis is an important factor affecting the overall survival rate of SACC (4). Current research on SACC primarily focuses on the investigation of primary lesions, but the pathogenesis of lung metastasis in SACC remains unknown (5). Thus, there is an urgent need to identify the key molecular mechanisms involved in the lung metastasis of SACC to improve clinical outcomes.

MicroRNAs (miRNAs/miRs) belong to a class of small non-coding RNAs that regulate gene expression post-transcriptionally and modulate cellular activities (6), such as apoptosis (7), tumour angiogenesis (8), cell invasion (9) and differentiation (10). miRNAs primarily function by inhibiting translation or/and cleaving the targeted mRNAs by pairing with their 3' untranslated regions (3'UTRs) (11). Previous studies have reported that miRNAs can affect the progression of SACC, such as the oncogenes miR-21 $(12,13)$ and miR-455-3p (14), and the tumour suppressors miR-320a (15) and miR-125a-5p (16). Therefore, investigations of the function of miRNAs and their targets may provide novel molecular markers for the diagnosis and treatment of SACC. miR-103a-3p has been examined in numerous studies, but its function remains controversial. For example, miR-103a-3p is considered to be an oncogene in colorectal cancer (17) and gastric cancer (18), but a tumour suppressor gene in glioma cells (19) and non-small cell lung cancer (20). Furthermore, to the best of our knowledge, the roles of miR-103a-3p in the progression of SACC and its underlying function in regulating tumour metastasis in SACC have not been previously reported. 
Tumour protein D52 (TPD52), a member of the TPD52-like protein family that is conserved among vertebrates, contains a small coiled-coil motif bearing small hydrophilic polypeptides and is mapped to chromosome 8q21 $(21,22)$. TPD52 exerts opposing roles in different tumours. High TPD52 expression is detected in prostate (23) and breast cancer (24), whereas low expression is observed in liposarcoma, clear cell renal cell cancer and lung cancer $(25,26)$. TPD52 has been shown to promote cell survival, proliferation, migration and invasion (27), however, previous studies have also revealed that TPD52 plays a suppressor role in the progression of tumours $(28,29)$. In addition, TPD52 can be regulated by miR-139-5p (30) and miR-15a-3p (31) to promote tumour progression. However, whether TPD52 has the same metastasis-promoting effect in SACC remains unknown, and the relationship between TPD52 and miR-103a-3p is yet to be elucidated.

The present study aimed to determine the expression of miR-103a-3p in SACC tissues and assess its effect on SACC progression. In addition, whether TPD52 is a direct binding target of miR-103a-3p was examined.

\section{Materials and methods}

Tissue sample and cell lines. The ten human SACC tissues and ten paired healthy submandibular gland (SMG) tissues (age, 42-68 years; female:male $=6: 4$ ) used for the tissue microarray were collected from patients with ACC at the Peking University School and Hospital of Stomatology (Beijing, China) between 2015.08 and 2016.04. The remining 52 human SACC (age, 31-75 years; female:male $=26: 26$ ) and 38 separate healthy SMG tissues used to analyse miR-103a-3p and TPD52 expression were collected between 2010.07 and 2018.07 at the Peking University School and Hospital of Stomatology. Patients had not undergone chemotherapy or radiation therapy, and the study was approved and followed the rules of the Ethics Committee of Peking University School and Hospital of Stomatology (permit no. PKUSSIRB-201522040). According to the relative gene expression of miR-103a-3p in 52 patients with SACC examined by reverse transcription-quantitative PCR (RT-qPCR), 52 patients were classified into the high or low miR-103a-3p group depending on the median miR-103a-3p relative gene expression. When the miR-103a-3p expression level of SACC tissue was higher than the median miR-103a-3p expression, the SACC tissue was classified into the high miR-103a-3p group, otherwise the SACC tissue was classified into the low miR-103a-3p group.

The SACC-83 cell line originated from ACC tissue from a patient with SACC in November 1983 (32). The SACC-LM cell line had enhanced lung metastatic features and was isolated following injection of SACC- 83 cells into the tail vein of immunodeficient mice $(33,34)$. The SACC-83 and SACC-LM cell lines were collected by the author SLL and kept at Peking University School and Hospital of Stomatology. SACC-83 and SACC-LM cells were cultivated in RPMI-1640 medium supplemented with 10\% FBS (both from Gibco; Thermo Fisher Scientific, Inc.). The primary epithelial cells of the SMG (SMG-E or pSMG) cells were derived from the sublingual gland of a 4-year-old boy in November 2016, with cell cultivation performed as previously described (35).
Exosomes isolation from cells supernatants was performed using ultracentrifugation and sucrose cushion. Cell supernatants were subjected to consecutive centrifugation at $300 \mathrm{x} \mathrm{g}$ for $10 \mathrm{~min}, 2,000 \mathrm{xg}$ for $30 \mathrm{~min}$ and $10,000 \mathrm{x} \mathrm{g}$ for $30 \mathrm{~min}$ to remove cellular debris and large vesicles at $4^{\circ} \mathrm{C}$. The supernatants were then passed through a Centrifugal Filter (100K; EMD Millipore) to concentrate the solution, followed by a $30 \%$ sucrose/deuterium oxide (D2O) cushion. After gradient centrifugation at $100,000 \times \mathrm{g}$ for $70 \mathrm{~min}$ using an Optima L-90K Ultracentrifuge (Beckman Coulter, Inc.) at $4^{\circ} \mathrm{C}$, the exosome-enriched sucrose/D2O was then re-suspended in PBS and the retained exosomes were stored at $-80^{\circ} \mathrm{C}$. All the isolation procedures were performed at room temperature.

The microarray analysis of tissues (ten human SACC tissues vs. ten paired SMG tissues) and cell exosomes (SACC-83 cells vs. SACC-LM cells) was performed by Shanghai Biotechnology Corporation.

RNA isolation and RT-qPCR analysis. Total RNA was extracted from tissues or cells using TRIzol ${ }^{\circledR}$ reagent (Invitrogen; Thermo Fisher Scientific, Inc.) according to the manufacturer's protocol. Reverse transcription was performed with the GoScript ${ }^{\mathrm{TM}}$ Reverse Transcription System (cat. no. A5001; Promega Corporation) according to the manufacturer's protocol. The procedure used for reverse transcription was as follows: $25^{\circ} \mathrm{C}$ for $5 \mathrm{~min}, 42^{\circ} \mathrm{C}$ for $60 \mathrm{~min}, 70^{\circ} \mathrm{C}$ for $15 \mathrm{~min}$ followed by hold at $4^{\circ} \mathrm{C}$. PCR reactions were performed on an ABI 7500 Sequence Detection System (Thermo Fisher Scientific, Inc.) using FastStart Universal SYBR Green Master (ROX) reagent (Roche Diagnostics GmbH). The thermocycling procedure used for amplification was as follows: Initial denaturation at $50^{\circ} \mathrm{C}$ for $2 \mathrm{~min}, 95^{\circ} \mathrm{C}$ for $10 \mathrm{~min}$, followed by 40 cycles at $95^{\circ} \mathrm{C}$ for $15 \mathrm{sec}$ and $60^{\circ} \mathrm{C}$ for $1 \mathrm{~min}$. Dissociation curves were used to assess amplification specificity. cDNA was synthesized for RT-qPCR using the following primer: miR-103a-3p, 5'-GTCGTATCCAGTGCAGGGTCCG AGGTATTCGCACTGGATACGACTCATAG-3'. RT-qPCR was conducted using the following primers: miR-103a-3pforward (F), 5'-CGCGAGCAGCATTGTACAGGG-3' and reverse (R), 5'-ATCCAGTGCAGGGTCCGAGG-3'; U6-F, 5'-CGAATTTGCGTGTCATCCT-3' and R, 5'-GCTTCGGC AGCACATACTAA-3'; TPD52-F, 5'-TCGGAAGAGGAGCA GGAAGAGC-3' and R, 5'-AGATGTTGCTGTCACGTCTT GCC-3'; and GAPDH-F, 5'-CCTGCCGTCTAGAAACCTG-3' and R, 5'-AGTGGGTGTCGCTGTTGAAGT-3'. Relative gene expression was calculated using the $2^{-\Delta \Delta \mathrm{Cq}}$ method (36).

Cell transfection. For miR-103a-3p overexpression and interference, miR-103a-3p mimics or miR-103a-3p inhibitor and their negative controls (NCs) were purchased from Guangzhou RiboBio Co., Ltd. The miR-103a-3p mimics and mimic NC were composed of a double-strand structure. The miR-103a-3p mimics sequences were as follows: Sense, 5'-AGCAGCAUUGU ACAGGGCUAUGA-3' andantisense, 3'-UCGUCGUAACAUG UCCCGAUACU-5'. The miR-103a-3p mimic NC sequences were as follows: Sense, 5'-UUUGUACUACACAAAAGUA CUG-3' and antisense, 3'-AAACAUGAUGUGUUUUCAU GAC-5'. The miR-103a-3p inhibitor sequence was: 5'-UCAUAG CCCUGUACAAUGCUGCU-3'. The miR-103a-3p inhibitor NC sequence was: 5'-CAGUACUU UUGUGUAGUACAAA-3'. 
To knockdown or overexpress TPD52, two small interfering (si)RNAs specific for TPD52 (siTPD52) and NC siRNAs were purchased from Guangzhou RiboBio Co., Ltd., and a recombinant vector overexpressing TPD52 (TPD52-OE) GV146-CMV-MCS-IRES-EGFP-SV40-neomycin and an empty vector were purchased from Shanghai GeneChem Co., Ltd. The TPD52 siRNA sequences were as follows: 5'-GAC TCTGTCTCAAGTGTTA-3' (siRNA1) and 5'-GCGGAAACT TGGAATCAAT-3' (siRNA2). The siRNA control sequence was: 5'-TTTCTCCGAACGTGTCACG-3'. SACC-83 and SACC-LM cells were transfected with miR-103a-3p mimics, miR-103a-3p inhibitor, TPD52 siRNA, the TPD52-OE vector or the empty vector and their NCs using Lipofectamine ${ }^{\circledR} 2000$ reagent (Invitrogen; Thermo Fisher Scientific, Inc.) according to the manufacturer's protocol. miR-103a-3p mimics, TPD52 siRNA and their NC were transfected into cells at a final concentration of $50 \mathrm{nM}$, and miR-103a-3p inhibitor and inhibitor $\mathrm{NC}$ at a final concentration of $100 \mathrm{nM}$. The plasmid of transfection was $2 \mu \mathrm{g} /$ well in 6-well plates. The transfections were performed at $37^{\circ} \mathrm{C}$ for $48 \mathrm{~h}$ when the cells grew up to $50-60 \%$ confluence. Subsequent experimentations were performed $48 \mathrm{~h}$ post-transfection.

Wound healing assay. For the wound healing assay, SACC-83 and SACC-LM cells were transfected 2 days in 6-well plate (50-60\% confluence), then the transfected cells were digested, counted and seeded into a $96-$ well plate $\left(3 \times 10^{4}\right.$ per well). Wound areas were measured using an IncuCyte instrument (Essen Bioscience, Inc.). Briefly, $\sim 3 \times 10^{4}$ tumour cells in RPMI-1640 medium supplemented with $10 \%$ FBS were seeded into 96-well plates. After reaching confluence, the cells were cultured in serum-free RPMI-1640 medium, and after $12 \mathrm{~h}$, a reproducible and uniform scratch wound was made using a WoundMaker ${ }^{\mathrm{TM}}$ (Essen BioScience, Inc.) in all wells. After washing three times with PBS, the cells were incubated in medium without FBS at $37^{\circ} \mathrm{C}$ for $48 \mathrm{~h}$ and the migration width change in the scratch wound was observed using an IncuCyte instrument at X10 magnification (light microscope). Migration widths were analysed by IncuCyte $^{\mathrm{TM}}$ ZOOM (version 2016A; Essen BioScience, Inc.).

Transwell migration assay. SACC-83 and SACC-LM cells transfected with miR-103a-3p mimics, miR-103a-3p inhibitor, TPD52 siRNA or TPD52-OE vector were seeded into the upper chamber of cell culture inserts (pore size, $8 \mu \mathrm{m}$; Falcon; Corning, Inc.) at a density of $8 \times 10^{4}$ cells/well. The cells in the upper chamber were cultured in RPMI-1640 medium without serum. The lower chamber contained $600 \mu \mathrm{l}$ RPMI-1640 medium supplemented with $20 \%$ FBS. Then, the chamber was incubated at $37^{\circ} \mathrm{C}$ under a humidified atmosphere containing $5 \% \mathrm{CO}_{2}$ for $19 \mathrm{~h}$. After the incubation, the cells on the lower surface of the insert were stained with a $1 \%$ crystal violet solution for $10 \mathrm{~min}$ after fixation with $95 \%$ ethanol for $30 \mathrm{~min}$, and the process of fixation and stain were performed at room temperature. Then, cells on the lower surface were imaged under a BX51 fluorescence microscope (Olympus Corporation) at x20 magnification. In total, six fields were randomly selected in each group for counting and statistical analysis. The statistical analysis was performed by GraphPad Prism (version 7.00; GraphPad Software, Inc.). Every experiment was repeated independently $\geq 3$ times.
Western blot analysis. Transfected cells were lysed in RIPA protein lysis buffer (Beyotime Institute of Biotechnology). The protein concentration was measured with a Pierce ${ }^{\mathrm{TM}}$ Bicinchoninic Acid Protein Assay kit (Thermo Fisher Scientific, Inc.), following the manufacturer's protocol. Each protein sample (40 $\mu \mathrm{g} /$ lane) was separated by $10-12 \%$ SDS-PAGE and transferred onto PVDF membranes. The membranes were blocked with 5\% non-fat milk in TBST (20 mM Tris, $137 \mathrm{mM}$ $\mathrm{NaCl}$ and $0.1 \%$ Tween-20, $\mathrm{pH}$ 7.4) for $1 \mathrm{~h}$ at room temperature. Then, the PVDF membranes were incubated with primary antibodies in blocking buffer overnight at $4{ }^{\circ} \mathrm{C}$ and followed by an incubation with horseradish peroxidase-conjugated goat anti-rabbit (1:100,000; cat.no.ZB-2301; OriGene Technologies, Inc.) or anti-mouse (1:100,000; cat. no. ZB-2305; OriGene Technologies, Inc.) IgG antibodies for $1 \mathrm{~h}$ at room temperature. The primary antibodies used were anti- $\beta$-actin $(1: 1,000$; cat. no. TA-09; OriGene Technologies, Inc.), anti-TPD52 (1:1,000; cat. no. ab182578; Abcam), anti-E-cadherin [1:1,000; cat. no. 3195; Cell Signalling Technology, Inc. (CST)], anti-N-cadherin $(1: 1,000$; cat. no. 13116; CST), anti-vimentin (1:1,000; cat. no. 5741; CST), anti-Snail (1:1,000; cat. no. 3879; CST) and anti-Slug (1:1,000; cat. no. 9585; CST). The immunocomplexes were visualized with a SuperEnhanced chemiluminescence detection kit (CWBIO). All bands were quantified using ImageJ (version 1.8.0; National Institutes of Health), and three independent experiments with three biological replicates each were performed.

Dual-luciferase reporter gene assay. The pEZX-MT05 plasmid was used to construct the TPD52 3'UTR luciferase reporter gene plasmid (iGene Biotechnology, Co., Ltd.). Wild-type (wt) or mutant (mut) 3'UTRs of TPD52 were cloned into the downstream sites of the pEZX-MT05 vector (iGene Biotechnology, Co., Ltd.). Next, $50 \mathrm{nM}$ miR-103a-3p mimics or $\mathrm{NC}$ and $2.5 \mu \mathrm{g}$ TPD52-wt or TPD52-mut were co-transfected into SACC cells using Lipofectamine ${ }^{\circledR} 2000$ (Invitrogen; Thermo Fisher Scientific, Inc.) according to the manufacturer's protocol. After $48 \mathrm{~h}$, the cell culture medium was collected and the activities of Gaussia Luciferase (GLuc) and Secreted Alkaline Phosphatase (SEAP) in the culture medium were assayed using a Secrete-Pair ${ }^{\mathrm{TM}}$ Luminescence Assay kit (cat. No. SPDA-D010; GeneCopoeia, Inc.) according to the manufacturer's protocol. The Gaussia Luciferase (Gluc) and Secreted Alkaline Phosphatase (SEAP) for each sample were measured using a Centro LB 960 Microplate Luminometer (Titertek-Berthold). Using SEAP signal as an internal standard control, signal normalization (ratio of GLuc and SEAP activities) eliminated the impact of transfection efficiency variations and made the normalized GLuc activities of samples of comparison more accurately reflect the true biological events. The ratio of luminescence intensities (RLU, relative light unit) of the GLuc was calculated over SEAP. Then, the normalized GLuc activity (GLuc/SEAP ratio) was compared with all samples.

Mouse model of lung metastasis. To elucidate the role of miR-103a-3p in SACC lung metastasis in vivo, 19 female NOD/SCID mice (age, 6 weeks; weight 20-25 g) were purchased from the Beijing Vital River Laboratory Animal Technology Co., Ltd. Animals were maintained under specific 

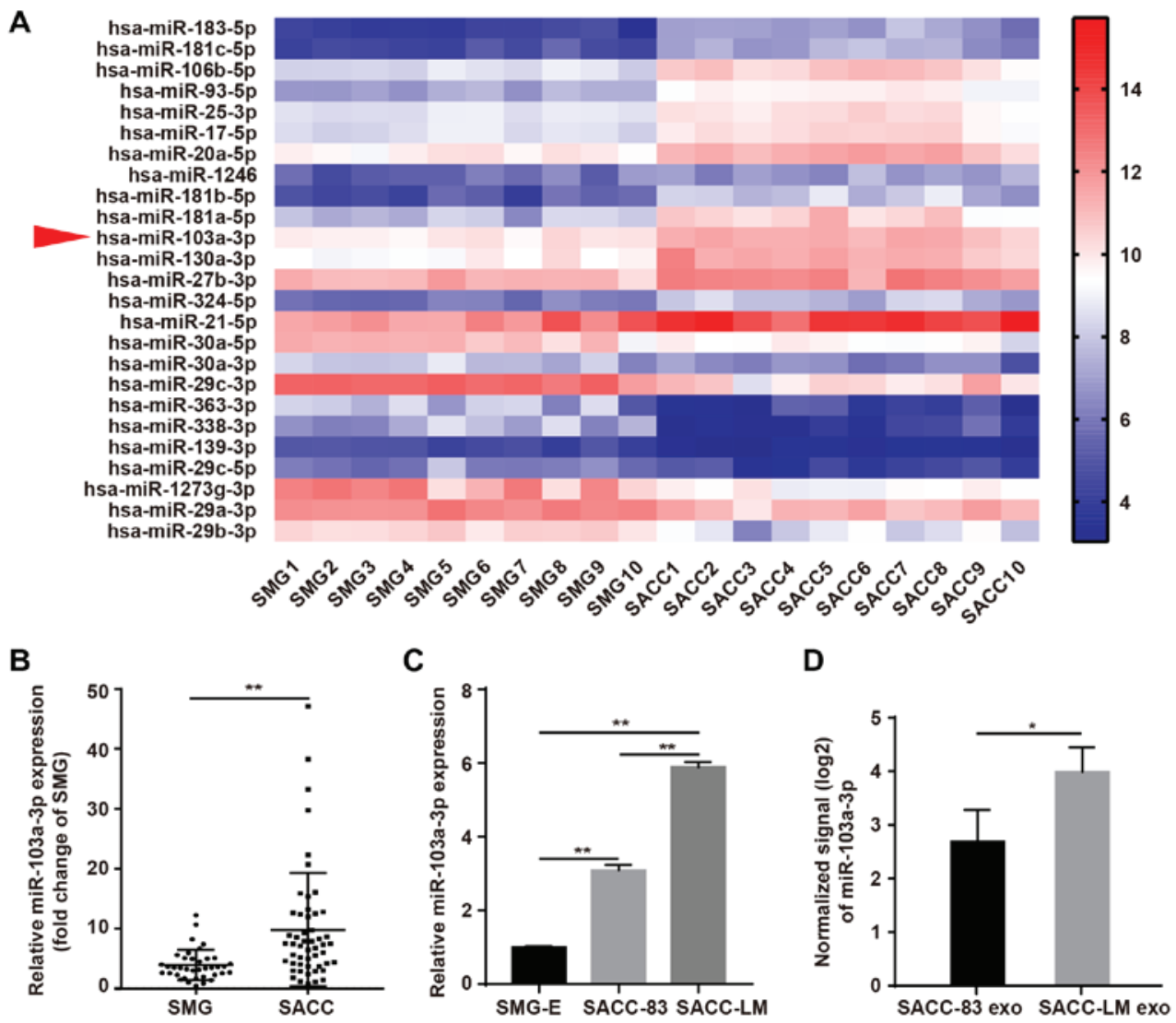

Figure 1. miR-103a-3p is overexpressed in SACC tissues and cells. (A) Microarray screening of differentially expressed miRNAs in ten human SACC tissues and paired SMG tissues. The 15 most upregulated miRNAs and ten most downregulated miRNAs are presented in the heat map. The red arrow denotes miR-103a-3p. (B) Determination of miR-103a-3p expression in 52 human SACC tissues and 38 human SMG tissues by RT-qPCR. (C) Determination of miR-103a-3p expression in SMG-E, SACC-83 and SACC-LM cells by RT-qPCR. (D) miRNA array analysis of miR-103a-3p expression in SACC-83 and SACC-LM cell exosomes. "P<0.05, ${ }^{* *} \mathrm{P}<0.01$. SACC, salivary adenoid cystic carcinoma; SMG, submandibular gland; SMG-E, submandibular gland primary epithelial cells; RT-qPCR, reverse transcription-quantitative PCR; miRNA/miR, microRNA; exo, exosomes.

pathogen-free conditions at room temperature $\left(20-26^{\circ} \mathrm{C}\right)$ with a humidity level of 50-60\%, a 12-h light/dark cycle and food and water ad libitum in the animal facility of Peking University School and Hospital of Stomatology. All efforts were made to minimize animal suffering. All animal assays were performed following approval from the Peking University Institutional Animal Care and Use Committee (Beijing, China; permit no. LA2015099). SACC-83 cells transfected with miR-103a-3p mimics or NC $\left(1 \times 10^{6}\right.$ cells $/ 100 \mu 1 /$ mouse $)$ were injected into the tail vein of NOD/SCID mice. During the whole experiment, the animals were carefully monitored at least twice a week. The maximum percentage of body weight loss observed in mice was $<12 \%$ from start to endpoint. The mice would be euthanized if they showed serious symptoms including, but not limited to, breathing difficulties, weight loss ( $>20 \%$ of body weight), vocalization, irritability, hunching, stationary, ruffling or poor grooming. The time to detect the tumour metastases in vivo was determined according to our previous experiment (34). After 8 weeks, the mice injected with miR-103a-3p mimics $(\mathrm{n}=9)$ or mimic $\mathrm{NC}(\mathrm{n}=10)$ transfected cells were sacrificed by cervical dislocation, and the procedure was performed out of sight of the other mice. The mortality of the mouse was verified by respiratory arrest and cardiac cessation. Subsequently, the lung tissues were collected from these mice. A maximum of two macroscopic nodules were observed in one lung tissue and the maximum diameter of a nodule was $4 \mathrm{~mm}$. Then, the lung tissues were fixed in $4 \%$ paraformaldehyde for $24 \mathrm{~h}$ at room temperature, embedded in paraffin and cut into 5- $\mu \mathrm{m}$ thick sections. These sections were subjected to haematoxylin and eosin (H\&E) staining to analyse the number of lung metastasis nodules (light microscope; $x 40$ magnification). Sections were deparaffinised and rehydrated with xylene I, xylene II and xylene III for 20 min each. Then, absolute ethanol I and absolute ethanol II for 10 min each and finally 95, 90, 80 and $70 \%$ ethanol for $5 \mathrm{~min}$. The sections were wash with deionized water three times for 3 min each time, then stained with haematoxylin for 2-3 min. Next, the sections were rinsed with deionized water for $10 \mathrm{~min}$ and stained with eosin for $1 \mathrm{~min}$. Gradient dehydration was performed with 70, 80, 90, 95 and $100 \%$ ethanol for 2, 2, 3, 3 and $10 \mathrm{~min}$, respectively, and then with xylene I, xylene II and xylene III for 10 min each. The sections were sealed with neutral gum and placed in a ventilated room overnight. All the procedures were performed at room temperature.

Statistical analysis. Statistical analyses, including two-tailed unpaired Student's t-test, one-way ANOVA with Bonferroni post-test correction, $\chi^{2}$ test and Pearson correlation coefficient analysis, were conducted with SPSS (version 20.0; SPSS, Inc.). Data are presented as the mean \pm standard deviation of 
Table I. Associations between clinicopathological variables and miR-103a-3p expression in patients with salivary adenoid cystic carcinoma.

\begin{tabular}{|c|c|c|c|c|c|}
\hline \multirow[b]{2}{*}{ Variables } & \multicolumn{3}{|c|}{ miR-103a-3p expression } & \multirow[b]{2}{*}{$\chi^{2}$} & \multirow[b]{2}{*}{ P-value } \\
\hline & Total (n) & Low $(n)$ & $\operatorname{High}(\mathrm{n})$ & & \\
\hline Age, years & & & & 0.746 & 0.388 \\
\hline$<42$ & 19 & 11 & 8 & & \\
\hline$\geq 42$ & 33 & 15 & 18 & & \\
\hline Sex & & & & 2.769 & 0.096 \\
\hline Male & 26 & 16 & 10 & & \\
\hline Female & 26 & 10 & 16 & & \\
\hline Tumour size & & & & 0.087 & 0.768 \\
\hline$<4 \mathrm{~cm}$ & 35 & 17 & 18 & & \\
\hline$\geq 4 \mathrm{~cm}$ & 17 & 9 & 8 & & \\
\hline Clinical stage $^{\mathrm{a}}$ & & & & 0.361 & 0.548 \\
\hline $\mathrm{I} / \mathrm{II}$ & 16 & 9 & 7 & & \\
\hline III/IV & 36 & 17 & 19 & & \\
\hline Site & & & & 0.433 & 0.510 \\
\hline Major salivary gland & 12 & 5 & 7 & & \\
\hline Minor salivary gland & 40 & 21 & 19 & & \\
\hline Lymph node metastasis & & & & 0.391 & 0.532 \\
\hline Absent & 38 & 20 & 18 & & \\
\hline Present & 14 & 6 & 8 & & \\
\hline Perineural invasion & & & & 0.000 & 1.000 \\
\hline Absent & 24 & 12 & 12 & & \\
\hline Present & 28 & 14 & 14 & & \\
\hline Lung metastasis & & & & 3.900 & 0.048 \\
\hline Absent & 40 & 23 & 17 & & \\
\hline Present & 12 & 3 & 9 & & \\
\hline Local regional recurrence & & & & 4.457 & 0.035 \\
\hline Absent & 42 & 24 & 18 & & \\
\hline Present & 10 & 2 & 8 & & \\
\hline Pathological type & & & & 0.000 & 1.000 \\
\hline Cribriform/tubular & 34 & 17 & 17 & & \\
\hline Solid & 18 & 9 & 9 & & \\
\hline
\end{tabular}

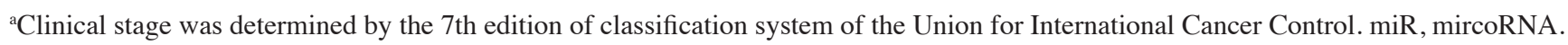

three independent experiments. These results were repeated in $\geq 3$ independent experiments. $\mathrm{P}<0.05$ was considered to indicate a statistically significant difference.

\section{Results}

miR-103a-3p is highly expressed in SACC tissues and SACC cells. To identify dysregulated miRNAs in SACC, the expression of miRNAs in SMG vs. SACC tissues was compared by microarray. GraphPad Prism was used to create the heat map generated from ten human SACC and ten paired SMG tissues, which demonstrated that miR-103a-3p ranked 11th among the top 15 upregulated miRNAs (Fig. 1A).

To evaluate the biological function of miR-103a-3p in SACC, its expression was measured in 38 SMG and 52 SACC tissues. miR-103a-3p expression was significantly higher in SACC tissues compared with healthy tissues (Fig. 1B). In addition, miR-103a-3p expression was significantly higher in SACC cells compared with SMG-E (Fig. 1C). Furthermore, SACC-LM cells had increased miR-103a-3p expression compared with SACC-83 cells. The expression of miR-103a-3p was also examined in SACC cell exosomes, and the results indicated that miR-103a-3p was significantly upregulated in SACC-LM cell exosomes (Fig. 1D).

The clinicopathological features of 52 patients with SACC were assessed and the results are presented in Table I. All the patients with SACC were classified into the high or low miR-103a-3p group depending on the median miR-103a-3p expression. High miR-103a-3p expression was associated with the local regional recurrence and lung metastasis. However, 
A

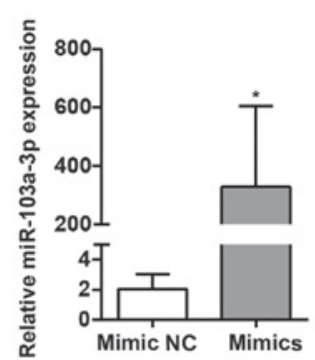

C

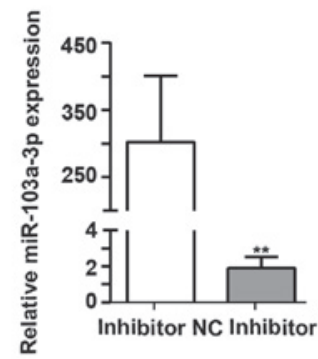

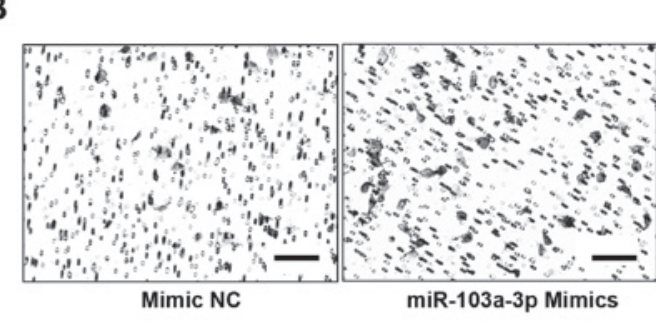

D

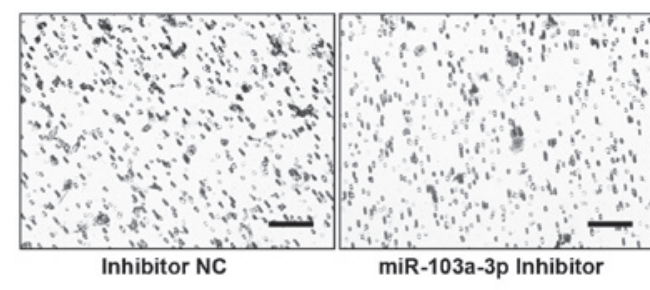

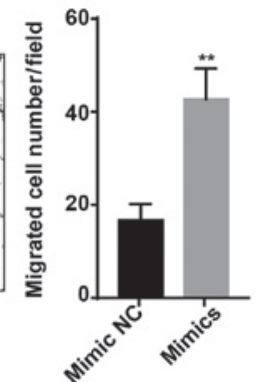

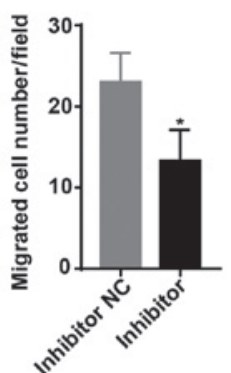

E

$\mathrm{Oh}$ $12 \mathrm{~h}$ $24 \mathrm{~h}$

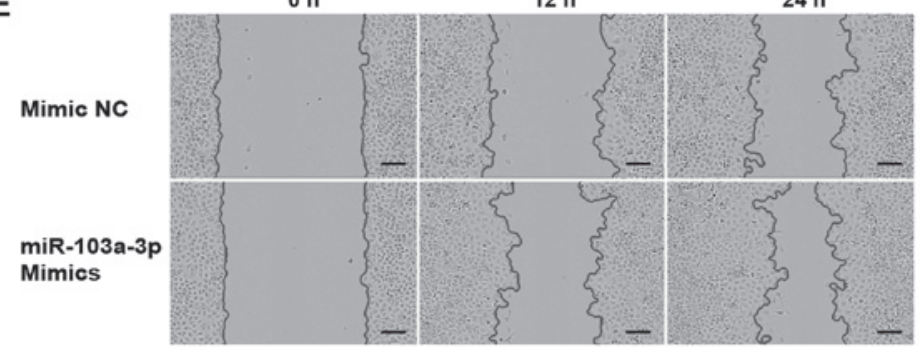

$\mathbf{F}$

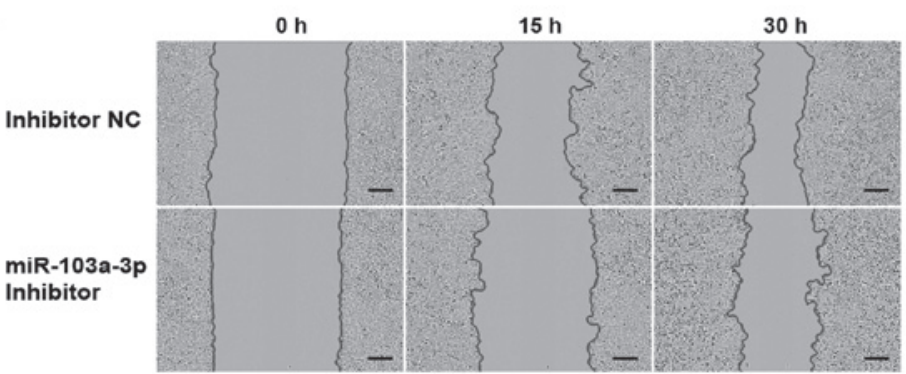

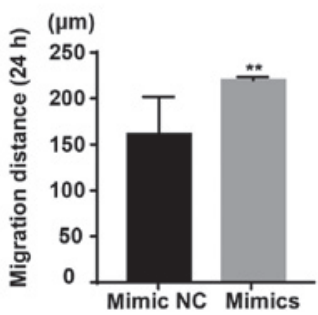

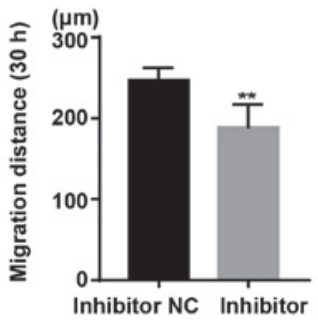

Figure 2. miR-103a-3p promotes the migration of SACC cells in vitro. (A) RT-qPCR analysis of miR-103a-3p expression after SACC-83 cells were transiently transfected with miR-103a-3p mimics and miR-103a-3p mimic NC. (B) Transwell migration assays of SACC-83 cells transfected with miR-103a-3p mimics and miR-103a-3p mimic NC. Scale bar, $100 \mu \mathrm{m}$. (C) RT-qPCR analysis of miR-103a-3p expression after SACC-LM cells were transiently transfected with an miR-103a-3p inhibitor and miR-103a-3p inhibitor NC. (D) Transwell migration assays of SACC-LM cells transfected with miR-103a-3p inhibitor and miR-103a-3p inhibitor NC. Scale bar, $100 \mu \mathrm{m}$. (E) Wound healing assays of miR-103a-3p mimic-transfected and miR-103a-3p mimic NC-transfected SACC-83 cells. Scale bar, $150 \mu \mathrm{m}$. (F) Wound healing assays of miR-103a-3p inhibitor-transfected and miR-103a-3p inhibitor NC-transfected SACC-LM cells. Scale bar, $150 \mu \mathrm{m}$. Data are presented as the mean \pm standard deviation of three independent experiments. ${ }^{*} \mathrm{P}<0.05,{ }^{* *} \mathrm{P}<0.01$. RT-qPCR, reverse transcription-quantitative PCR; NC, negative control; miR, microRNA; SACC, salivary adenoid cystic carcinoma.

no significant associated was identified between miR-103a-3p expression and the other clinicopathological features, including age, sex, tumour size, clinical stage, site, lymph node metastasis, perineural invasion and pathological type. Collectively, these results indicated that miR-103a-3p serves as an oncogene in SACC.

miR-103a-3p modulates cell migration and the epithelial-mesenchymal transition (EMT) process in vitro. To investigate the function of miR-103a-3p, miR-103a-3p mimics and a mimic NC were transfected into SACC-83 cells (Fig. 2A), and then the effect of miR-103a-3p on cell migration was assessed using a Transwell migration assays. The Transwell migration assay results demonstrated that significantly more cells migrated in the miR-103a-3p mimic group compared with the NC group (Fig. 2B). Subsequently, miR-103a-3p expression was knocked down to assess its migration effects in SACC-LM cells using a miRNA inhibitor (Fig. 2C). The Transwell assay results indicated that significantly fewer cells migrated in the miR-103a-3p inhibitor group compared with the inhibitor NC group (Fig. 2D). The effects of miR-103a-3p on cell proliferation were also assessed using a Cell Counting Kit-8, and it was found that miR-103a-3p had no significant effect on the proliferation of SACC cells (Data S1; Fig. S1).

The effect of miR-103a-3p on cell migration were also examined using wound healing assay. Compared with the NC group, the migratory distance of SACC- 83 cells transiently transfected with miR-103a-3p mimics was 
A

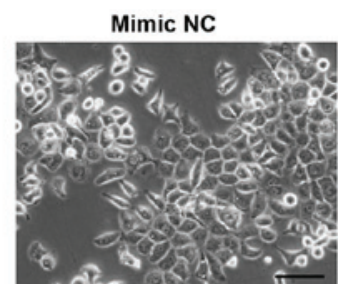

C
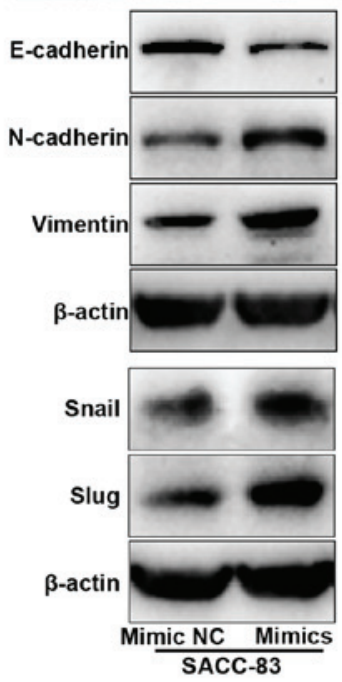

miR-103a-3p Mimics
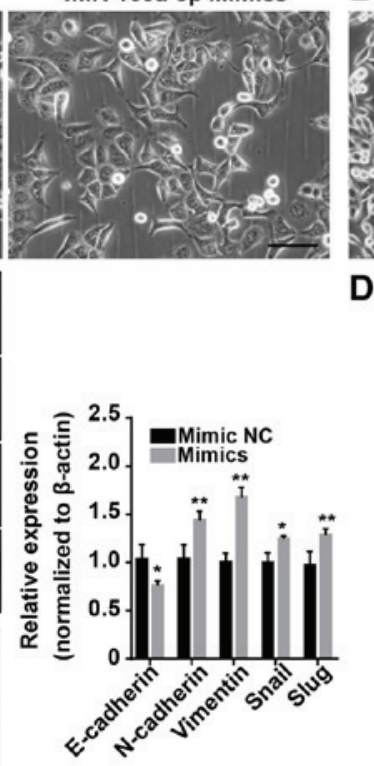

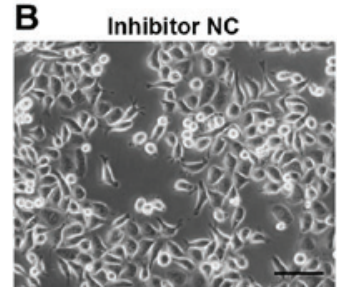

miR-103a-3p Inhibitor

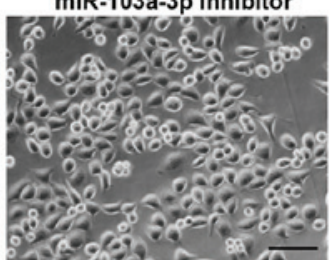

D

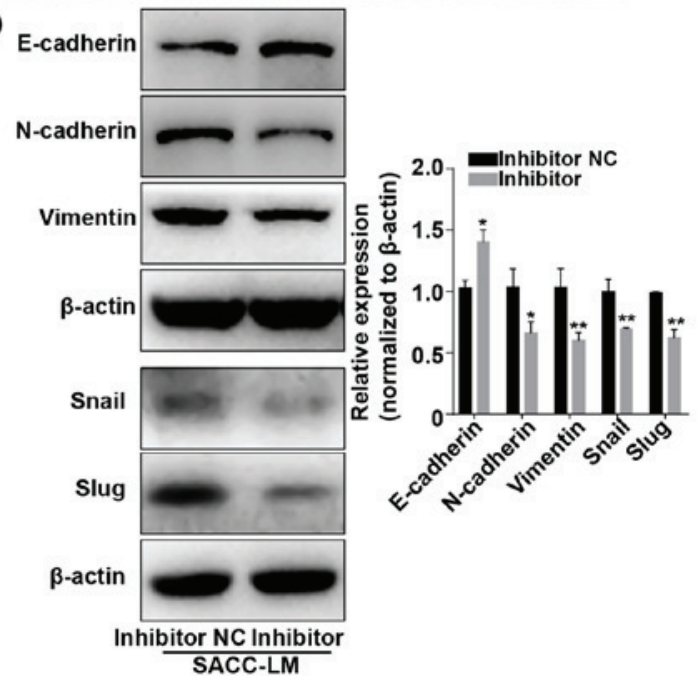

E

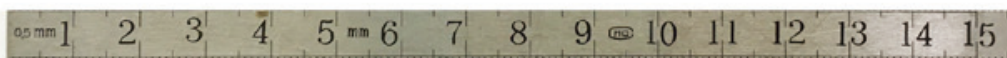

Mimic NC
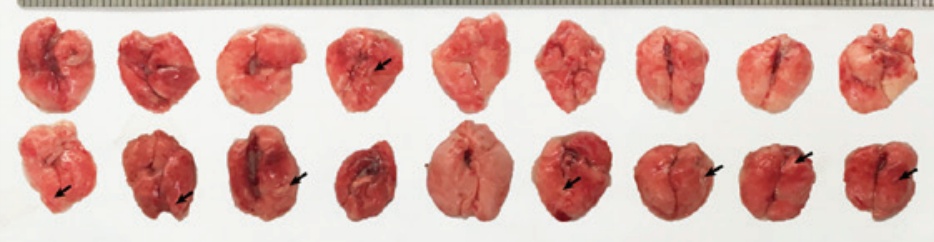

$\mathbf{F}$

Mimic NC

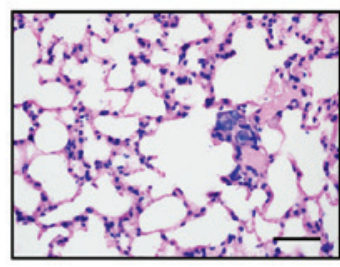

miR-103a-3p Mimics

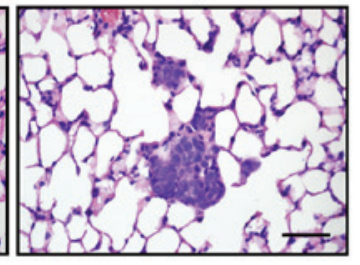

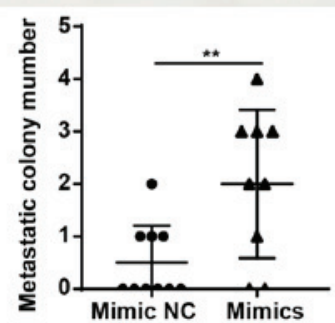

Figure 3. miR-103a-3p overexpression promotes and miR-103a-3p knockdown inhibits the EMT process in vitro and mouse lung metastasis in vivo. (A) Phase-contrast microscopy results identified fibroblastic morphological EMT changes in miR-103a-3p mimic-transfected SACC-83 cells compared with mimic NC cells. Scale bar, $100 \mu \mathrm{m}$ (B) Phase-contrast microscopy results of the epithelial morphological EMT changes in miR-103a-3p inhibitor-transfected SACC-LM cells compared with inhibitor NC-transfected cells. Scale bar, $100 \mu \mathrm{m}$. (C) Western blotting of miR-103a-3p mimic-transfected and miR-103a-3p mimic NC-transfected SACC-83 cells (left); semi-quantification of protein bands in transfected SACC-83 cells (right). (D) Western blotting of miR-103a-3p inhibitor-transfected and miR-103a-3p inhibitor NC-transfected SACC-LM cells (left); semi-quantification of protein bands in transfected SACC-LM cells (right). (E) Image of lung tissues from xenograft NOD mice. The arrows indicate lung metastatic tumour nodules. (F) Images of haematoxylin and eosin staining of metastatic tumour nodules in lung tissues after tail vein injection of miR-103a-3p mimic-transfected and miR-103a-3p mimic NC-transfected SACC-83 cells (left) and quantification of the metastatic colony number (right). Scale bar, $100 \mu \mathrm{m}$. Data are presented as the means \pm standard deviation of three independent experiments. ${ }^{*} \mathrm{P}<0.05,{ }^{* *} \mathrm{P}<0.01$. NC, negative control; miR, microRNA; EMT, epithelial-mesenchymal transition.

significantly wider (Fig. 2E). Furthermore, migration was slower in the miR-103a-3p inhibitor group compared with the control group (Fig. 2F). It was also demonstrated that the mimic-transfected SACC-83 cells had a fibroblast-like morphology (Fig. 3A), while knockdown of miR-103a-3p in SACC-LM cells resulted in an epithelial-like morphology (Fig. 3B).

Next, the changes in EMT markers were evaluated. In the miR-103a-3p mimic group, the mesenchymal cell markers
$\mathrm{N}$-cadherin, vimentin, Slug and Snail were significantly upregulated, while the epithelial cell marker E-cadherin was significantly downregulated (Fig. 3C). When miR-103a-3p was inhibited, E-cadherin was significantly upregulated, and $\mathrm{N}$-cadherin, Slug, Snail and Vimentin were significantly downregulated (Fig. 3D). Therefore, these results suggested that miR-103a-3p can affect cell function via the EMT process and that miR-103a-3p plays a role in promoting SACC metastasis. 
A
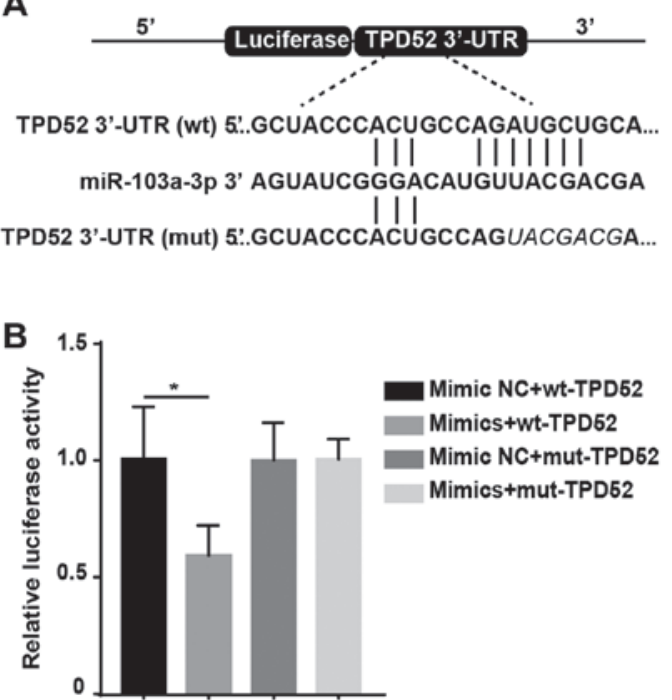

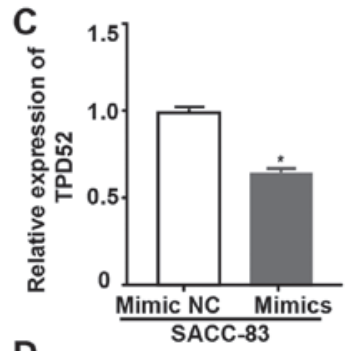

D

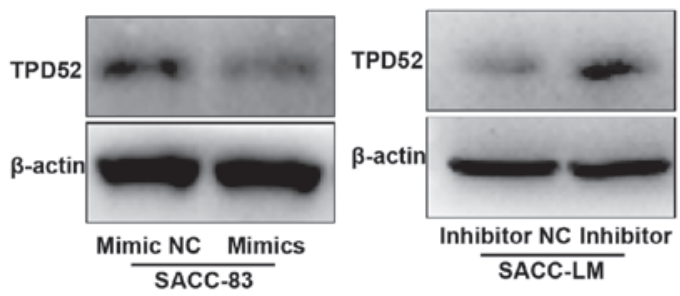

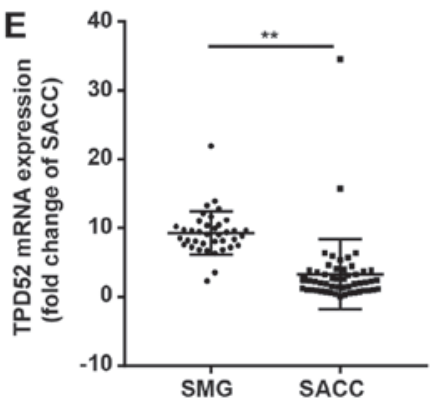
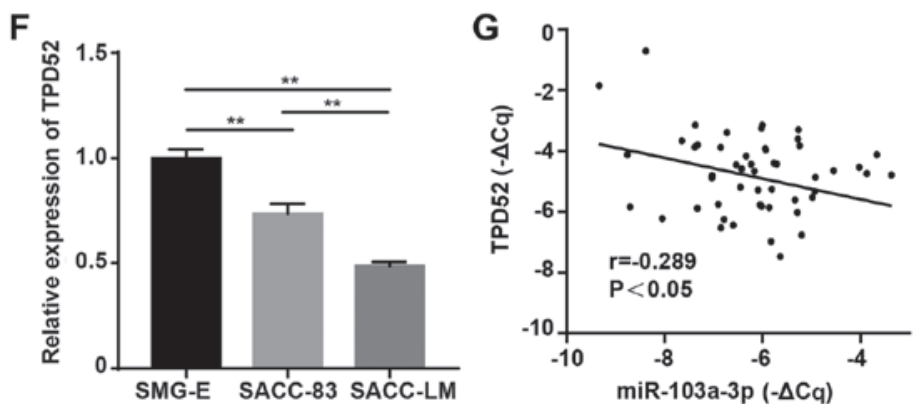

Figure 4. TPD52 is a direct target gene of miR-103a-3p. (A) Schematic diagram of the binding sites of miR-103a-3p to the 3'UTR of TPD52 mRNA predicted by TargetScan, miRTarBase and miRDB and the mutant sites. (B) Relative luciferase activity was assessed in SACC-83 cells that were transfected with the wt 3'UTR TPD52 construct or mut 3'UTR TPD52 construct, as well as miR-103a-3p mimic NC or miR-103a-3p mimics. (C) RT-qPCR analysis of TPD52 mRNA expression after SACC cells were transiently transfected with miR-103a-3p mimics and inhibitor. (D) Western blot analysis of TPD52 protein expression after SACC cells were transiently transfected with miR-103a-3p mimics and inhibitor. (E) Determination of the expression of TPD52 mRNA in 52 human SACC tissues and 38 human SMG tissues by RT-qPCR. (F) Determination of the expression of TPD52 mRNA in SMG-E, SACC-83 and SACC-LM cells by RT-qPCR. (G) Correlation between miR-103a-3p expression and TPD52 mRNA in 52 SACC tissues. A negative correlation between miR-103a-3p and TPD52 mRNA was observed ( $\mathrm{P}<0.05 ; \mathrm{r}=-0.289)$. "P<0.05, ${ }^{* *} \mathrm{P}<0.01$. SACC, salivary adenoid cystic carcinoma; SMG, submandibular gland; SMG-E, submandibular gland primary epithelial cells; RT-qPCR, reverse transcription-quantitative PCR; NC, negative control; miR, microRNA; wt, wild-type; mut, mutant; TPD52, tumour protein D52.

Upregulation of miR-103a-3p promotes SACC cell metastasis in vivo. To investigate the effect of miR-103a-3p on SACC lung metastasis in vivo, miR-103a-3p mimic- and mimic NC-transfected SACC- 83 cells were injected into the tail veins of NOD/SCID mice. These mice were sacrificed after 8 weeks, and the lung tissues were collected, fixed, sectioned and subjected to H\&E staining. The mice injected with mimictransfected SACC- 83 cells had more visible tumour nodules compared with those with mimic NC-transfected SACC-83 cells. (Fig. 3E). Furthermore, the number and extent of lung tumour nodules was significantly greater in the mice injected with miR-103a-3p mimic-transfected cells compared with those injected with mimic NC-transfected cells (Fig. 3F). Thus, these results indicated that miR-103a-3p promotes SACC lung metastasis in vivo.

TPD52 is a direct target of miR-103a-3p in SACC. Next, the possible mechanism via which miR-103a-3p promotes the migration of SACC cells was investigated. The potential interaction of miR-103a-3p with target mRNAs was analysed using different prediction tools, including TargetScan (http://www. targetscan.org/vert_72/), miRTarBase (http://mirtarbase.mbc. nctu.edu.tw/php/index.php) and miRDB (http://mirdb.org/). TPD52 was identified as a target gene of miR-103a-3p (Fig. 4A). To determine whether TPD52 is a direct target of miR-103a-3p, wt and mut 3'UTRs of TPD52 were inserted downstream of the luciferase reporter vector (Fig. 4A). The luciferase reporter assay results demonstrated that miR-103a-3p overexpression significantly reduced luciferase activity in the TPD52-wt group (Fig. 4B) but not in the TPD52-mut group, indicating that miR-103a-3p can directly target TPD52.

RT-qPCR and western blotting results indicated that TPD52 mRNA and protein expression levels were decreased in miR-103a-3p mimic-transfected SACC-83 cells and increased in miR-103a-3p inhibitor-transfected SACC-LM cells (Fig. 4C and D). Moreover, the expression of TPD52 was measured in the 38 SMG and 52 SACC tissues by RT-qPCR. It was identified that TPD52 expression was significantly higher in healthy tissues compared with SACC tissues (Fig. 4E), which is controversial with the known function of miR-103a-3p. SACC-83 
A

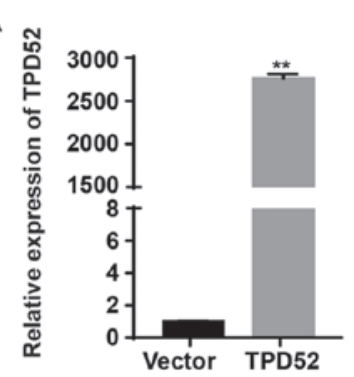

C

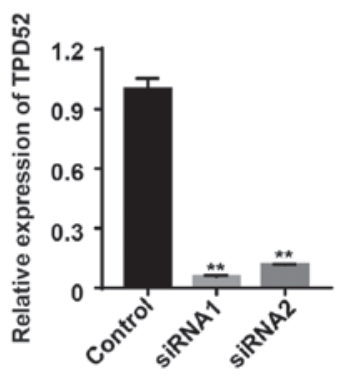

B

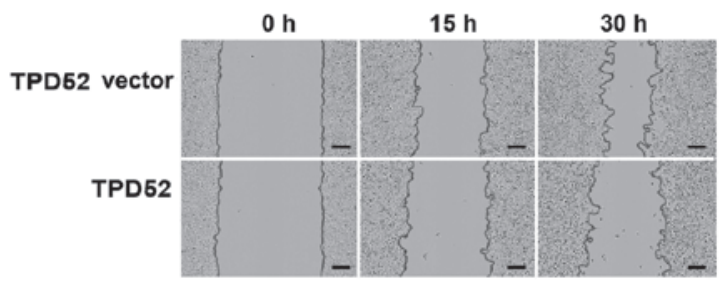

$\mathbf{0 ~ h}$

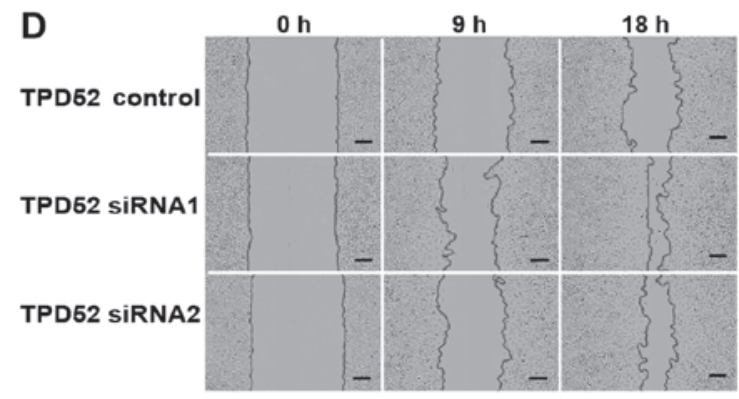

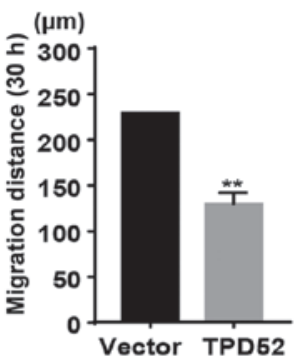

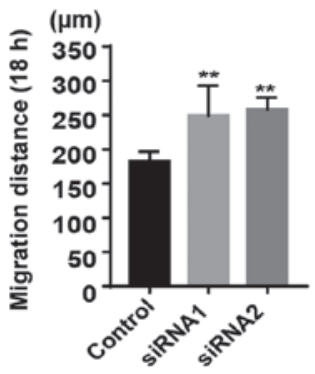

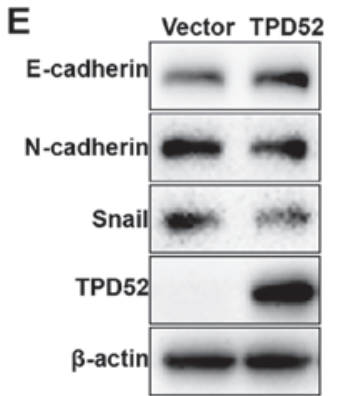
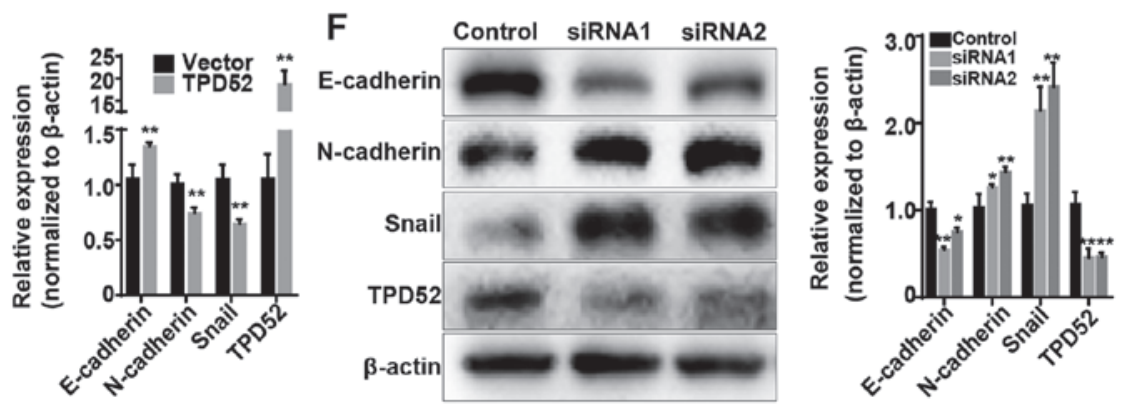

Figure 5. TPD52 overexpression inhibits, while knockdown promotes SACC cell migration and EMT. (A) RT-qPCR analysis of TPD52 mRNA expression after SACC-LM cells were transiently transfected with TPD52 overexpression plasmids and negative control vector. (B) Wound healing assays of TPD52 vector-transfected and TPD52 OE-transfected SACC-LM cells. Scale bar, $150 \mu \mathrm{m}$. (C) RT-qPCR analysis of TPD52 mRNA expression after SACC-83 cells were transiently transfected with TPD52 siRNA and negative control. (D) Wound healing assays of TPD52 siRNA-transfected and TPD52 control-transfected SACC-83 cells. Scale bar, $150 \mu \mathrm{m}$. (E) Western blotting of TPD52 vector-transfected and TPD52 OE-transfected SACC-LM cells (left); semi-quantification of protein bands in transfected SACC-LM cells (right). (F) Western blotting of TPD52 siRNA-transfected and TPD52 control-transfected SACC-83 cells (left); semi-quantification of protein bands in transfected SACC-83 cells (right). Data are presented as the mean \pm standard deviation of three independent experiments. ${ }^{*} \mathrm{P}<0.05,{ }^{* *} \mathrm{P}<0.01$. RT-qPCR, reverse transcription-quantitative PCR; siRNA, small interfering RNA; TPD52, tumour protein D52; SACC, salivary adenoid cystic carcinoma.

cells expressed significantly higher levels of TPD52 compared with SACC-LM cells (Fig. 4F). In addition, the relationship between miR-103a-3p and TPD52 was assessed by RT-qPCR and it was demonstrated that there was a significantly weak negative correlation between miR-103a-3p and TPD52 (Fig. 4G). Therefore, it was speculated that miR-103a-3p promoted cancer migration by targeting TPD52.

TPD52 promotes SACC progression. To investigate whether miR-103a-3p acts as an important cancer promoter by targeting TPD52, the function of TPD52 was evaluated in SACC cells. TPD52 was overexpressed using plasmid transfection. After transfection with a TPD52 recombinant plasmid, RT-qPCR and western blotting results indicated that the mRNA and protein expression levels of TPD52 were significantly increased in TPD52-OE vector-transfected SACC-LM cells (Fig. 5A and E). The effects of TPD52 on the proliferation of SACC cells were also assessed using a Cell Counting Kit-8 assay, and it was found that TPD52 had no significant effect on the proliferation of SACC cells (Fig. S2).
Subsequently, the function of TPD52 in tumour migration was investigated, and the wound healing assay results demonstrated that TPD52 overexpression significantly suppressed the migration of SACC-LM cells (Fig. 5B). In addition, TPD52 expression was downregulated by transfecting SACC-83 cells with two TPD52 siRNAs. RT-qPCR and western blotting results identified significant decreases in TPD52 mRNA and protein expression levels in TPD52 siRNA-transfected SACC-83 cells (Fig. 5C and F). It was also found that TPD52 knockdown promoted SACC-83 cell migration in wound healing assays (Fig. 5D). Furthermore, western blotting results indicated that TPD52 overexpression decreased the expression levels of the mesenchymal markers $\mathrm{N}$-cadherin and Snail, but increased that of the epithelial marker E-cadherin (Fig. 5E). When TPD52 was knocked down, there were significant increases in $\mathrm{N}$-cadherin and Snail but a significant decrease in E-cadherin (Fig. 5F). These data suggested that TPD52 inhibits the migration of SACC cells.

The associations between clinicopathological variables and TPD52 mRNA expression were examined in patients with 

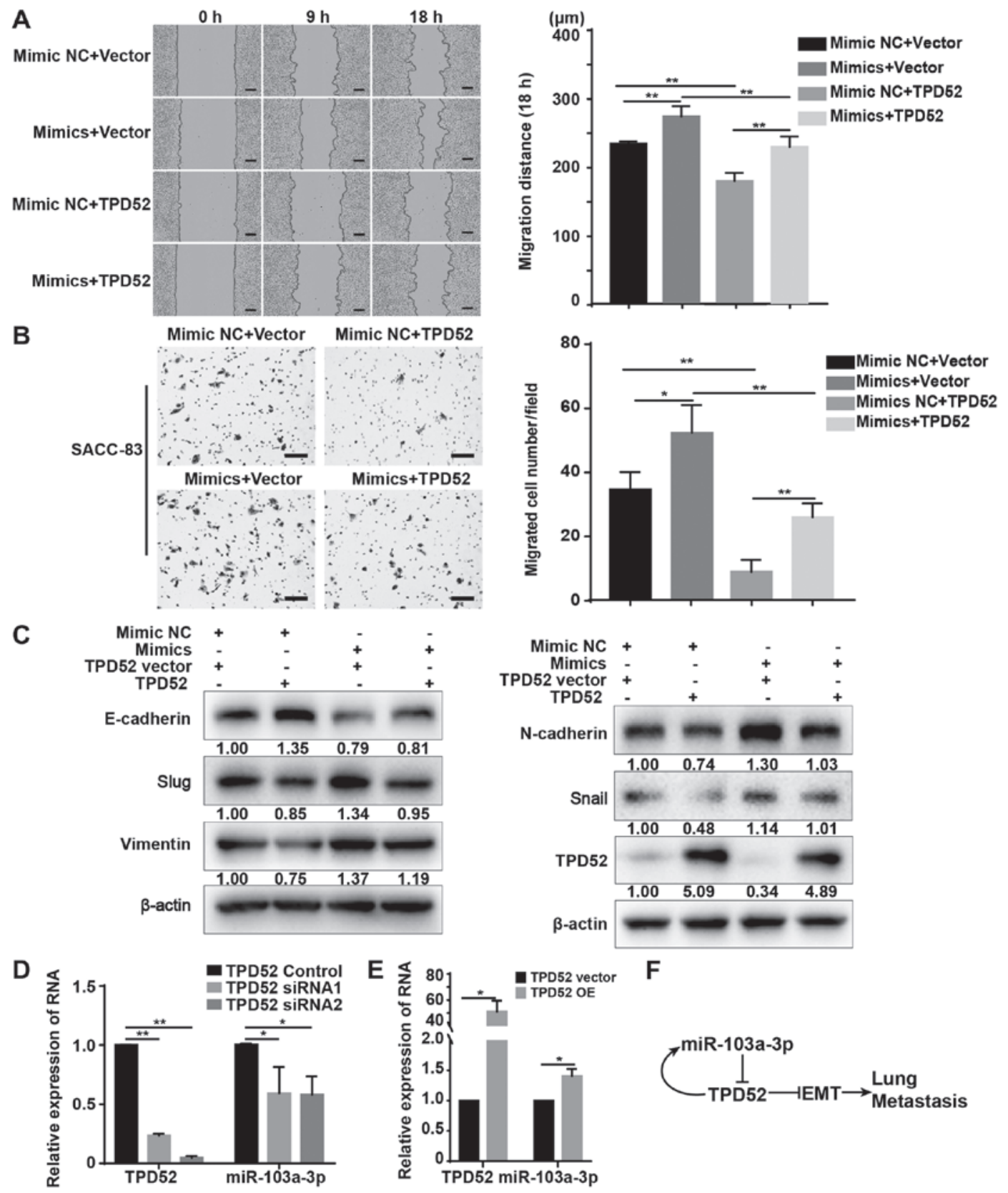

$\mathbf{F}$

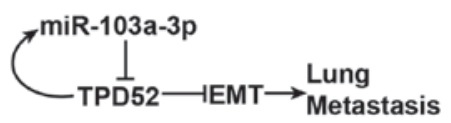

Figure 6. Overexpression of TPD52 abrogates miR-103a-3p-induced migration of SACC-83 cells. (A) Wound healing assay analysis of SACC-83 cells transiently transfected with miR-103a-3p mimics, TPD52 OE plasmid, negative control or vector for cell migration. Scale bar, $150 \mu \mathrm{m}$. (B) Transwell migration assays of SACC-83 cells transiently transfected with miR-103a-3p mimics, TPD52 OE plasmid, NC or vector. Scale bar, $100 \mu \mathrm{m}$. (C) Western blotting analysis the EMT markers of SACC-83 cells transiently transfected with miR-103a-3p mimics, TPD52 OE plasmid, NC or vector. (D) RT-qPCR analysis of miR-103a-3p expression after SACC-83 cells were transiently transfected with TPD52 siRNA and NC. (E) RT-qPCR analysis of miR-103a-3p expression after SACC-LM cells were transiently transfected with TPD52 OE plasmid and NC vector. (F) Schematic diagram of the role of miR-103a-3p and TPD52 in SACC lung metastasis. Data are presented as the mean \pm standard deviation of three independent experiments. ${ }^{*} \mathrm{P}<0.05$ and ${ }^{* *} \mathrm{P}<0.01$. RT-qPCR, reverse transcription-quantitative PCR; siRNA, small interfering RNA; TPD52, tumour protein D52; OE, overexpression; NC, negative control; miR, microRNA; SACC, salivary adenoid cystic carcinoma.

SACC, and the results are presented in Table SI. All patients with SACC were classified into high-TPD52 and low-TPD52 groups depending on the median TPD52 mRNA expression. Low TPD52 mRNA expression was associated with a high incidence of lung metastasis and a high rate of perineural invasion. However, no significant associations were observed between TPD52 expression and the other clinicopathological features.

miR-103-3p-induced EMT and migration of SACC cells is neutralized by TPD52 overexpression. To further verify whether the promoting effects of miR-103a-3p on SACC cell migration and EMT are mediated by targeting TPD52, cell phenotype changes were examined after overexpressing TPD52 in miR-103a-3p mimic-transfected SACC cells. The wound healing assay results suggested that TPD52 overexpression significantly decreased the migratory distance of miR-103a-3p mimic-transfected SACC cells compared with the mimics + vector groups (Fig. 6A). Furthermore, the Transwell migration assay results demonstrated a inhibitory effect in miR-103a-3p mimic SACC cells overexpressing TPD52 compared with the mimics + vector group (Fig. 6B). 
Western blotting results suggested that overexpressing TPD52 rescued the EMT effect of miR-103a-3p overexpression, as indicated by decreased expression of the mesenchymal markers N-cadherin, Vimentin, Snail and Slug, and increased expression of the epithelial marker E-cadherin in miR-103a-3p mimic-transfected SACC cells (Fig. 6C). These findings further indicated that overexpression of miR-103a-3p promotes SACC cell migration and EMT by targeting TPD52. TPD52 may also negatively regulate its own expression. Moreover, knockdown of TPD52 inhibited the expression of miR-103a-3p in SACC-83 cells (Fig. 6D), while TPD52 overexpression promoted the expression of miR-103a-3p in SACC-LM cells (Fig. 6E). The schematic diagram demonstrated the role of miR-103a-3p and TPD52 in SACC lung metastasis (Fig. 6F). miR-103a-3p promoted lung metastasis by targeting TPD52, and TPD52 moderated the expression of miR-103a-3p in turn.

\section{Discussion}

Metastasis activation is one of the hallmarks of cancer (37). Thus, understanding the regulatory molecules and mechanisms of metastasis is crucial for the diagnosis and treatment of tumours. Previous studies have reported that the expression profiles of miRNAs are abnormal in several types of cancer, and miRNAs can regulate the development of these cancer types $(15,38,39)$. It has also been revealed that numerous miRNAs may regulate the initiation, progression and metastasis of SACC $(14,40,41)$, and miR-103a-3p has been shown to regulate development in some specific malignant tumours $(18,20,42)$. However, the function and molecular mechanism of miR-103a-3p in SACC lung metastasis remain unknown. The present results suggested that miR-103a-3p was upregulated in SACC tissues and tumour cell lines. The overexpression of miR-103a-3p promoted migration in low-metastasis SACC-83 cells, while miR-103a-3p knockdown inhibited metastasis in high-metastasis SACC-LM cells. Further examination revealed that miR-103a-3p overexpression could promote the conversion of epithelial markers into interstitial markers and vice versa. Using in vivo miR-103a-3p gain-of-function studies, it was demonstrated that miR-103a-3p may act as a tumour promoter in SACC. The tumour metastasis promoting function of miR-103a-3p in SACC was consistent with its function in colorectal cancer (17) and gastric cancer (18).

miRNAs typically function by binding to the 3'UTR region of mRNA to reduce the mRNA expression of target genes (43). Therefore, it was speculated that miR-103a-3p acts as a tumour promoter by targeting specific mRNAs. Through prediction analyses, TPD52 was identified as a potential target of miR-103a-3p, and dual-luciferase reporter gene assay results verified this predicted target. RT-qPCR and western blotting results also indicated that miR-103a-3p overexpression could decrease the mRNA and protein expression levels of TPD52. Moreover, miR-103a-3p expression was negatively associated with TPD52 mRNA expression in SACC tissues, and overexpressing TPD52 could rescue the migration-promoting effect of miR-103a-3p. Thus, these findings suggested that miR-103a-3p binds to the 3'UTR region of TPD52 mRNA to decrease TPD52 expression.
TPD52 has significant roles in the malignant phenotype of cancer cells (27). Previous PCR results have shown that TPD52 was upregulated in 18/29 tested cancer types and downregulated in $11(38 \%)$ tumour types (25). It has also been reported that exogenous TPD52 expression promotes prostate cancer cell migration via $\alpha v \beta 3$ integrin by activating the protein kinase B/Akt signaling pathway (44) and that miR-139-5p can inhibit the proliferation, apoptosis and cell cycle of uterine leiomyoma cells by targeting TPD52 (30). However, TPD52 may also play an opposite role in different tumours. Previous studies have shown that decreased TPD52 expression was associated with poor prognosis in primary hepatocellular carcinoma (28) and that TPD52 could inhibit renal cell carcinoma cell metastasis via the PI3K/Akt signalling pathway (29). In the present study, TPD52 expression was lower in SACC tissues compared with SMG tissues. Furthermore, SACC-LM cells with high lung metastasis expressed less TPD52 compared with parental SACC-83 cells. Knockdown of TPD52 promoted SACC cell migration and the conversion of epithelial markers into interstitial markers, whereas TPD52 overexpression had the opposite results. Collectively, these results suggested that TPD52 may be a tumour suppressor gene in SACC and inhibits cancer cell migration.

As miR-103a-3p inhibited TPD52 expression, and TPD52 could in turn promote miR-103a-3p expression, TPD52 expression remained low in SACC cells. Therefore, it was speculated that the self-regulation of cells maintains balanced TPD52 expression: when cellular TPD52 expression was excessive, the enhanced expression of miR-103a-3p results in reduced TPD52 and sustained EMT in SACC cells. This finding suggests that the feedback regulation between miR-103a-3p and TPD52 maintains the metastatic properties of SACC.

The present study focused on the effects of miR-103a-3p on cell migration and lung metastasis. However, miRNAs can also exert effects on cell invasion (45), apoptosis (46) and angiogenesis (47). Another potential effect of miR-103a-3p may also be involved in lung metastasis processes, and future investigations should focus on determining whether more phenotypes and their associated molecular and signalling pathways are involved in the miR-103a-3p-mediated lung metastasis of SACC.

In conclusion, the present results demonstrated that miR-103a-3p acted as an oncogene in SACC by promoting tumour cell migration, which was promoted by miR-103a-3p via direct targeting of TPD52. The identification of the novel miR-103a-3p/TPD52 axis is significant for understanding SACC pathogenesis and offers further insight into the identification of novel biomarkers or potential therapeutic targets for SACC.

\section{Acknowledgements}

Not applicable.

\section{Funding}

This study was supported by the National Natural Science Foundation of China (grant no. 81872190). 


\section{Availability of data and materials}

The datasets used and/or analysed in the current study are available from the corresponding author upon reasonable request.

\section{Authors' contributions}

XYG and SLL designed the experiments. MF and CWC performed the in vitro experiments and acquired the data. $\mathrm{MF}$, CWC, ZHD and YRL collected tissue samples and performed the in vivo experiments. MF, LQY and WWY analysed and interpreted the data and performed statistical analysis. MF and LQY drafted the manuscript. All authors read and approved the final manuscript.

\section{Ethics approval and consent to participate}

Experiments using human tissue samples were approved by the Ethics Committee of Peking University School and Hospital of Stomatology (Beijing, China; permit no. PKUSSIRB-201522040). All participants signed written informed consent. All animal assays were performed following approval from the Peking University Institutional Animal Care and Use Committee (Beijing, China; permit no. LA2015099).

\section{Patient consent for publication}

Not applicable.

\section{Competing interests}

The authors declare that they have no competing interests.

\section{References}

1. Adelstein DJ, Koyfman SA, El-Naggar AK and Hanna EY: Biology and management of salivary gland cancers. Semin Radiat Oncol 22: 245-253, 2012.

2. Rapidis AD, Givalos N, Gakiopoulou H, Faratzis G, Stavrianos SD, Vilos GA, Douzinas EE and Patsouris E: Adenoid cystic carcinoma of the head and neck. Clinicopathological analysis of 23 patients and review of the literature. Oral Oncol 41: 328-335, 2005.

3. Kokemueller H, Eckardt A, Brachvogel P and Hausamen JE: Adenoid cystic carcinoma of the head and neck - a 20 years experience. Int J Oral Maxillofac Surg 33: 25-31, 2004.

4. Gao M, Hao Y, Huang MX, Ma DQ, Luo HY, Gao Y, Peng X and Yu GY: Clinicopathological study of distant metastases of salivary adenoid cystic carcinoma. Int J Oral Maxillofac Surg 42: 923-928, 2013.

5. Coca-Pelaz A, Rodrigo JP, Bradley PJ, Vander Poorten V, Triantafyllou A, Hunt JL, Strojan P, Rinaldo A, Haigentz M Jr, Takes RP, et al: Adenoid cystic carcinoma of the head and neck An update. Oral Oncol 51: 652-661, 2015.

6. Bartel DP: MicroRNAs: Genomics, biogenesis, mechanism, and function. Cell 116: 281-297, 2004.

7. Benakanakere MR, Zhao J, Finoti L, Schattner R, Odabas-Yigit M and Kinane DF: MicroRNA-663 antagonizes apoptosis antagonizing transcription factor to induce apoptosis in epithelial cells. Apoptosis 24: 108-118, 2019.

8. Fang JH, Zhang ZJ, Shang LR, Luo YW, Lin YF, Yuan Y and Zhuang SM: Hepatoma cell-secreted exosomal microRNA-103 increases vascular permeability and promotes metastasis by targeting junction proteins. Hepatology 68: 1459-1475, 2018.

9. Liu X, Jiang L, Wang A, Yu J, Shi F and Zhou X: MicroRNA-138 suppresses invasion and promotes apoptosis in head and neck squamous cell carcinoma cell lines. Cancer Lett 286: 217-222, 2009.
10. Barbollat-Boutrand L, Joly-Tonetti N, Dos Santos M, Metral E, Boher A, Masse I, Berthier-Vergnes O, Bertolino P, Damour O and Lamartine J: MicroRNA-23b-3p regulates human keratinocyte differentiation through repression of TGIF1 and activation of the TGF- $\beta$-SMAD2 signalling pathway. Exp Dermatol 26: 51-57, 2017.

11. Lim LP, Lau NC, Garrett-Engele P, Grimson A, Schelter JM, Castle J, Bartel DP, Linsley PS and Johnson JM: Microarray analysis shows that some microRNAs downregulate large numbers of target mRNAs. Nature 433: 769-773, 2005.

12. Yan F, Wang C, Li T, Cai W and Sun J: Role of miR-21 in the growth and metastasis of human salivary adenoid cystic carcinoma. Mol Med Rep 17: 4237-4244, 2018.

13. Wang C, Li T, Yan F, Cai W, Zheng J, Jiang X and Sun J: Effect of simvastatin and microRNA-21 inhibitor on metastasis and progression of human salivary adenoid cystic carcinoma. Biomed Pharmacother 105: 1054-1061, 2018.

14. Brown AL, Al-Samadi A, Sperandio M, Soares AB, Teixeira LN, Martinez EF, Demasi APD, Araújo VC, Leivo I, Salo T, et al: miR-455-3p, miR-150 and miR-375 are aberrantly expressed in salivary gland adenoid cystic carcinoma and polymorphous adenocarcinoma. J Oral Pathol Med 48: 840-845, 2019.

15. Sun L, Liu B, Lin Z, Yao Y, Chen Y, Li Y, Chen J, Yu D, Tang Z, Wang B, et al: miR-320a acts as a prognostic factor and Inhibits metastasis of salivary adenoid cystic carcinoma by targeting ITGB3. Mol Cancer 14: 96, 2015.

16. Liang Y, Ye J, Jiao J, Zhang J, Lu Y, Zhang L, Wan D, Duan L, Wu Y and Zhang B: Down-regulation of miR-125a-5p is associated with salivary adenoid cystic carcinoma progression via targeting p38/JNK/ERK signal pathway. Am J Transl Res 9: 1101-1113, 2017.

17. Chen HY, Lin YM, Chung HC, Lang YD, Lin CJ, Huang J, Wang WC, Lin FM, Chen Z, Huang HD, et al: miR-103/107 promote metastasis of colorectal cancer by targeting the metastasis suppressors DAPK and KLF4. Cancer Res 72: 3631-3641, 2012.

18. Zheng J, Liu Y, Qiao Y, Zhang L and Lu S: miR-103 Promotes Proliferation and Metastasis by Targeting KLF4 in Gastric Cancer. Int J Mol Sci 18: 18, 2017.

19. Wang L, Liu Y and Song J: MicroRNA-103 suppresses glioma cell proliferation and invasion by targeting the brain-derived neurotrophic factor. Mol Med Rep 17: 4083-4089, 2018.

20. Yang D, Wang JJ, Li JS and Xu QY: miR-103 Functions as a Tumor Suppressor by Directly Targeting Programmed Cell Death 10 in NSCLC. Oncol Res 26: 519-528, 2018.

21. Chen Y, Kamili A, Hardy JR, Groblewski GE, Khanna KK and Byrne JA: Tumor protein D52 represents a negative regulator of ATM protein levels. Cell Cycle 12: 3083-3097, 2013.

22. Wilson SH, Bailey AM, Nourse CR, Mattei MG and Byrne JA: Identification of MAL2, a novel member of the mal proteolipid family, though interactions with TPD52-like proteins in the yeast two-hybrid system. Genomics 76: 81-88, 2001.

23. Rubin MA, Varambally S, Beroukhim R, Tomlins SA, Rhodes DR, Paris PL, Hofer MD, Storz-Schweizer M, Kuefer R, Fletcher JA, et al: Overexpression, amplification, and androgen regulation of TPD52 in prostate cancer. Cancer Res 64: 3814-3822, 2004.

24. Balleine RL, Fejzo MS, Sathasivam P, Basset P, Clarke CL and Byrne JA: The hD52 (TPD52) gene is a candidate target gene for events resulting in increased 8q21 copy number in human breast carcinoma. Genes Chromosomes Cancer 29: 48-57, 2000.

25. Tennstedt P, Bölch C, Strobel G, Minner S, Burkhardt L, Grob T, Masser S, Sauter G, Schlomm T and Simon R: Patterns of TPD52 overexpression in multiple human solid tumor types analyzed by quantitative PCR. Int J Oncol 44: 609-615, 2014.

26. Kumamoto T, Seki N, Mataki H, Mizuno K, Kamikawaji K, Samukawa T, Koshizuka K, Goto Y and Inoue H: Regulation of TPD52 by antitumor microRNA-218 suppresses cancer cell migration and invasion in lung squamous cell carcinoma. Int J Oncol 49: 1870-1880, 2016.

27. Byrne JA, Frost S, Chen Y and Bright RK: Tumor protein D52 (TPD52) and cancer-oncogene understudy or understudied oncogene? Tumour Biol 35: 7369-7382, 2014.

28. Wang Y, Chen CL, Pan QZ, Wu YY, Zhao JJ, Jiang SS, Chao J, Zhang XF, Zhang HX, Zhou ZQ, et al: Decreased TPD52 expression is associated with poor prognosis in primary hepatocellular carcinoma. Oncotarget 7: 6323-6334, 2016.

29. Zhao Z, Liu H, Hou J, Li T, Du X, Zhao X, Xu W, Xu W and Chang J: Tumor Protein D52 (TPD52) Inhibits Growth and Metastasis in Renal Cell Carcinoma Cells Through the PI3K/Akt Signaling Pathway. Oncol Res 25: 773-779, 2017. 
30. Chen H, Xu H, Meng YG, Zhang Y, Chen JY and Wei XN: miR-139-5p regulates proliferation, apoptosis, and cell cycle of uterine leiomyoma cells by targeting TPD52. OncoTargets Ther 9: 6151-6160, 2016.

31. Wu Y, Huang J, Xu H and Gong Z: Over-expression of miR-15a-3p enhances the radiosensitivity of cervical cancer by targeting tumor protein D52. Biomed Pharmacother 105: 1325-1334, 2018.

32. Li SL: Establishment of a human cancer cell line from adenoid cystic carcinoma of the minor salivary gland. Zhonghua Kou Qiang Yi Xue Za Zhi 1990 (In Chinese).

33. Dong L, Wang YX, Li SL, Yu GY, Gan YH, Li D and Wang CY: TGF-beta1 promotes migration and invasion of salivary adenoid cystic carcinoma. J Dent Res 90: 804-809, 2011.

34. Yang W-W, Yang L-Q, Zhao F, Chen CW, Xu LH, Fu J, Li SL and Ge XY: Epiregulin Promotes Lung Metastasis of Salivary Adenoid Cystic Carcinoma. Theranostics 7: 3700-3714, 2017.

35. Xu LH, Zhao F, Yang WW, Chen CW, Du ZH, Fu M, Ge XY and Li SL: MYB promotes the growth and metastasis of salivary adenoid cystic carcinoma. Int J Oncol 54: 1579-1590, 2019.

36. Livak KJ and Schmittgen TD: Analysis of relative gene expression data using real-time quantitative PCR and the 2(-Delta Delta C(T)) Method. Methods 25: 402-408, 2001.

37. Hanahan D and Weinberg RA: Hallmarks of cancer: The next generation. Cell 144: 646-674, 2011.

38. Zhu Y, Gu J, Li Y, Peng C, Shi M, Wang X, Wei G, Ge O, Wang D, Zhang B, et al: miR-17-5p enhances pancreatic cancer proliferation by altering cell cycle profiles via disruption of RBL2/E2F4-repressing complexes. Cancer Lett 412: 59-68, 2018.

39. Zhang X, Wang S, Wang H, et al: Circular RNA circNRIP1 acts as a microRNA-149-5p sponge to promote gastric cancer progression via the AKT1/mTOR pathway. Mol Cancer 18: 20, 2019.
40. Andreasen S, Tan Q, Agander TK, Hansen TVO, Steiner P, Bjørndal K, Høgdall E, Larsen SR, Erentaite D, Olsen CH, et al: MicroRNA dysregulation in adenoid cystic carcinoma of the salivary gland in relation to prognosis and gene fusion status: A cohort study. Virchows Arch 473: 329-340, 2018.

41. He Q, Zhou X, Li S, Jin Y, Chen Z, Chen D, Cai Y, Liu Z, Zhao T and Wang A: MicroRNA-181a suppresses salivary adenoid cystic carcinoma metastasis by targeting MAPK-Snai2 pathway. Biochim Biophys Acta 1830: 5258-5266, 2013.

42. Natarelli L, Geissler C, Csaba G, Wei Y, Zhu M, di Francesco A, Hartmann P, Zimmer R and Schober A: miR-103 promotes endothelial maladaptation by targeting lncWDR59. Nat Commun 9: 2645,2018

43. Wu L, Fan J and Belasco JG: MicroRNAs direct rapid deadenylation of mRNA. Proc Natl Acad Sci USA 103: 4034-4039, 2006.

44. Ummanni R, Teller S, Junker H, Zimmermann U, Venz S, Scharf C, Giebel J and Walther R: Altered expression of tumor protein D52 regulates apoptosis and migration of prostate cancer cells. FEBS J 275: 5703-5713, 2008

45. Croset M, Pantano F, Kan CWS, Bonnelye E, Descotes F, Alix-Panabières $\mathrm{C}$, Lecellier $\mathrm{CH}$, Bachelier R, Allioli N, Hong SS, et al: miRNA-30 Family Members Inhibit Breast Cancer Invasion, Osteomimicry, and Bone Destruction by Directly Targeting Multiple Bone Metastasis-Associated Genes. Cancer Res 78: 5259-5273, 2018.

46. Xu Z, Li Z, Wang W, Xia Y, He Z, Li B, Wang S, Huang X, Sun G, Xu J, et al: MIR-1265 regulates cellular proliferation and apoptosis by targeting calcium binding protein 39 in gastric cancer and, thereby, impairing oncogenic autophagy. Cancer Lett 449: 226-236, 2019.

47. Dai J, Wang J, Yang L, Xiao Y and Ruan Q: miR-125a regulates angiogenesis of gastric cancer by targeting vascular endothelial growth factor A. Int J Oncol 47: 1801-1810, 2015. 